\title{
Detection of Toxoplasma gondii from Clinical Specimens of Patients Receiving Renal Transplant Using ELISA and PCR
}

\author{
Morteza Izadi ${ }^{1}$, Nematollah Jonaidi Jafari ${ }^{1}$, Abbas Mahmoodzadeh Poornaki ${ }^{2}$, Javid Sadraei ${ }^{3}$, \\ Babak Rezavand ${ }^{2,}$, Hamid Reza Mirzaei ${ }^{4}$, Hossein Zarrinfar $^{5}$, Abulfazl Khedive ${ }^{6}$ \\ ${ }_{1}^{1}$ Health Research Center, Baqiyatallah University of Medical Sciences, Tehran, IR Iran \\ ${ }_{3}^{2}$ Department of Parasitology, School of Medicine, Zanjan University of Medical Sciences, Zanjan, IR Iran \\ ${ }^{3}$ Parasitology Department of Medical School, Tarbiat Modares University, Tehran, IR Iran \\ 4 Department of Immunology, School of Medicine, Tehran University of Medical Sciences, Tehran, IR Iran \\ 5 Department of Medical Parasitology and Mycology, Ghaem Hospital, School of Medicine, Mashhad University of Medical Sciences, Mashhad, IR Iran \\ 6 Bayer Paul (BP) Vaccine and Pharmaceutical Company, Tehran, IR Iran \\ *Corresponding author: Babak Rezavand, Department of Parasitology, School of Medicine, Zanjan University of Medical Sciences, Zanjan, IR Iran. Tel: +98-2414240301; Ext: 3, Fax: +98-
} 2414249553, E-mail: babak80@gmail.com.

Received: July 17, 2013; Accepted: August 17, 2013

\begin{abstract}
Background:Toxoplasmagondiiisan opportunisticparasiticorganismcausinginfectioninmanymammals, includingimmunosuppressed patients. Toxoplasmosis as an opportunistic infection is highly prevalent among patients receiving a kidney transplant.

Objectives:The purpose of this study was to identify and determine the prevalence of Toxoplasma gondii in clinical samples collected from patients receiving renal transplants.

Patients and Methods: A total of 50 blood samples and 40 lung lavage samples from transplanted patients admitted to the infectious wards and the patients undergoing bronchoscopy were collected. The B1 Gene of Toxoplasma gondii was amplified using PCR of the blood and bronoalveolar lavage BAL samples, and IgG and IgM antibodies against Toxoplasma were detected in serum samples using ELISA.

Results: Our results indicated that anti-toxoplasma specific IgG and IgM antibodies were prevalent among transplant recipients with values of $54 \%$ and $4 \%$ respectively. PCR was performed to detect Toxoplasma gondii in 3 blood and lavage samples (3.3\%) with $100 \%$ sensitivity and $97.9 \%$ specificity.

Conclusions: Toxoplasma gondii pulmonary infection is measured along with brain toxoplasmosis in patients receiving a kidney transplant. After serological methods, PCR is the second useful method for Toxoplasma gondii screening. Proper prophylaxis before and after receiving a kidney transplant together with Toxoplasma gondii screening of donor and transplant is recommended.
\end{abstract}

Keywords: Toxoplasma; Kidney Transplantation; Enzyme-Linked Immunosorbent Assay; Polymerase Chain Reaction

\section{Background}

Toxoplasmosis is a zoonotic disease which infects all nucleated cells, but it cannot survive and multiply within red blood cells (1). for the first time in 1908, Toxoplasma gondii was detected by Nicolle and Manceaux in liver and spleen samples of the small rodent Ctenodactylus gondii (2). Felids are the definitive hosts of the microorganism, and most other mammals are known as the intermediate hosts. Toxoplasma gondii infection in humans can be divided into congenital or acquired infections (3). Toxoplasma gondii infection is seen in patients in two acute and chronic forms. When the immune system of human body is active, the cystic form of the parasite is observed (chronic form) but in the immune-compromised cases and patients with deficiency in immune system, active form of the parasite is presented, and then the clinical manifestations reveal (4). Life-threatening disease occurs in immunocompromised hosts such as AIDS patients, organ transplant recipients and patients with malignancies who are undergoing chemotherapy. The risk of acute toxoplasmosis among transplant patients who had not received anti- Toxoplasma gondii prophylaxis is remarkably high (5). The diagnosis of toxoplasmosis is mainly based on serological tests of disease-specific antibodies, imaging and molecular diagnosis using the clinical specimens (6).

Immunosuppressed patients infected with Toxoplasma gondii show symptoms such as diffuse encephalopathy, meningoencephalitis, extensive brain lesions and pneumonia (7). Toxoplasma pneumonia in immunosuppressed individuals caused $55 \%$ of the mortalities (8). Patients received organ transplant administrate immunosuppressive drugs to prevent the rejection of the organ. Immunosuppression influences the patient resistance to a variety 
of opportunistic pathogens like Toxoplasma gondii (9). Early diagnosis of toxoplasmosis along with proper treatment can prevent serious consequences of infection (10).

\section{Objectives}

Due to the increasing number of patients receiving kidney transplants in our country, the aim of this study was to identify and determine the prevalence of Toxoplasma gondii among patients receiving a kidney transplant in Tehran.

\section{Patients and Methods}

This cross-sectional study was conducted on patients receiving kidney transplants. The samples were collected from patients admitted to specialized hospitals in Tehran due to various infections as well as the patients undergoing bronchoscopy. A total of 50 blood and 40 BAL samples were collected from specialized hospitals in Tehran to evaluate the titer of anti-Toxoplasma gondii antibody, 5 $\mathrm{mL}$ blood was taken from patients, and was divided into two equal portions in vials. Blood samples were moved to the laboratory immediately. For serological tests, serum was separated by centrifugation at1000rpmfor 5 minutes. The serums were kept at $-20^{\circ} \mathrm{C}$ until the start of the experiments.

\subsection{ELISA}

ELISA for detection of anti-toxoplasma IgG and IgM antibodies was conducted using VIRO-IMMUN kit (Germany) according to the kit protocol. To measure the amount of IgG and IgM antibodies, 50 serum samples from renal transplant recipients were collected.

\subsection{DNA Extraction}

DNA was extracted from whole blood and BAL samples, using DNA extraction kit of MTB manufactured by Roche company, according to the manufacture protocol. The DNA extracted from whole blood samples and BAL was kept at- $80^{\circ} \mathrm{C}$ until PCR was performed.

\subsection{PCR}

The specific primers TR1: (5'-ACGAACACTCGCAGAGATGA-3 ${ }^{\prime}$ ) and TR2: (5 -GATCCTTTTGCACGGTTGTT-3') was designed for B1 Gene. Deionized water was used as negative control, and RH strain (derived from an asymptomatic child with initials of R.H.) provided in Department of Parasitology of Tarbiat Modares University was used as positive control.

PCR was performedin a final volume of $25 \mu \mathrm{L}$ by adding $0.8 \mu \mathrm{L}$ of magnesium chloride, dNTP, Taq polymerase enzyme, $2.5 \mu \mathrm{L}$ PCR buffer, DNA template and $1 \mu \mathrm{L}$ of primers at a concentration of $1 \mathrm{PM}$.

Each of 35 cycles of PCR thermal was consisted of an initial denaturation cycle for 3 minutes at $94^{\circ} \mathrm{C}$, denaturation of DNA for 30 seconds at $94^{\circ} \mathrm{C}$, annealing for $30 \mathrm{sec}$ onds at $45^{\circ} \mathrm{C}$, extension for 30 seconds at $72^{\circ} \mathrm{C}$ and final extension for 5 minutes at $72^{\circ} \mathrm{C} .10 \mu \mathrm{L}$ of the amplified PCR product was analyzed on $1.5 \%$ agarose gel electrophoresis and visualized under Transluminatorafter ethidium bromide staining.

\subsection{Statistical Analysis}

In order to measure the significance testing between age and IgG, IgM titers and PCR, independent T-test was conducted. To find the relationship between gender, duration of transplant and IgG and IgM titers and PCR, the

Table 1. Diagnosis of Toxoplasma gondii in Blood Sample of Kidney Transplantations Patients Using ELISA and PCR

\begin{tabular}{|c|c|c|c|c|c|c|c|}
\hline & Total & IgG Positive & P Value & IgM Positive & PValue & PCR Positive & PValue \\
\hline $\begin{array}{l}\text { Duration of trans- } \\
\text { plantation, No. (\%) }\end{array}$ & & & 0.7 & & 0.5 & & 0.99 \\
\hline More than 6 months & $21(42)$ & $12(57.1)$ & & $0(0)$ & & $1(4.8)$ & \\
\hline Less than 6 months & $29(58)$ & $15(51.7)$ & & $2(6.9)$ & & $2(6.9)$ & \\
\hline Age, Mean (SD), y & $35.54(11)$ & $37.74(10.67)$ & 0.13 & $33.50(13.43)$ & 0.79 & $30.66(10.69)$ & 0.44 \\
\hline Gender, No. (\%) & & & 0.001 & & 0.99 & & 0.57 \\
\hline Female & $21(42)$ & $8(27.6)$ & & $1(4.8)$ & & $2(9.5)$ & \\
\hline Male & $29(58)$ & $19(90.5)$ & & $1(3.4)$ & & $1(3.4)$ & \\
\hline
\end{tabular}

fisher exact test was performed. All differences were considered significant at the level of $\mathrm{P}<0.05$. All statistical analysis was performed using the Statistical software for the social sciences (SPSS) version 20 (Chicago, Inc., USA).

\section{Results}

Of the 90 patients selected for study, 29 were female (32.2\%) and 61 male (67.8\%). The mean age was $36.62 \pm 12.14$ years. ELISA was applied to measure anti-Toxoplasma IgG and IgM antibodies. The results showed that among 50 
blood samples of renal transplant patients, 27 patients (54\%) were positive for IgG antibody and 2 patients (4\%) were positive for IgM antibodies. Toxoplasma gondii -specific DNA amplification using PCR of blood and lung lavage samples collected from renal transplant patients revealed that 3 blood samples (6\%) and 2 lung lavage samples (5\%) were positive (Tables 1 and 2 ).

Positive samples were detected by presenting a $120 \mathrm{bp}$ band of amplification test on 1.5\% agarose gel (Figure 1).

Sensitivity and specificity of PCR was measured according to the gold diagnosis standard of Toxoplasma gondii (i.e. ELISA). The studies showed that the sensitivity and

Table 2. Molecular Diagnosis of Toxoplasma gondii in Lavage Sample of Kidney Transplantations Patients

\begin{tabular}{llll}
\hline & Count & PCR Positive, No.(\%) & P Value \\
\hline $\begin{array}{l}\text { Duration of Trans- } \\
\text { plantation }\end{array}$ & & & 0.14 \\
More than 6 months & 25 & $0(0)$ & \\
\hline Less than 6 months & 15 & $2(13.3)$ & \\
\hline Age, Mean (SD),y & & $37.97(13.39)$ & 0.23 \\
Gender, & & & 0.99 \\
\hline Female & 8 & $0(0)$ & \\
\hline Male & 32 & $2(6.2)$ & \\
\hline
\end{tabular}

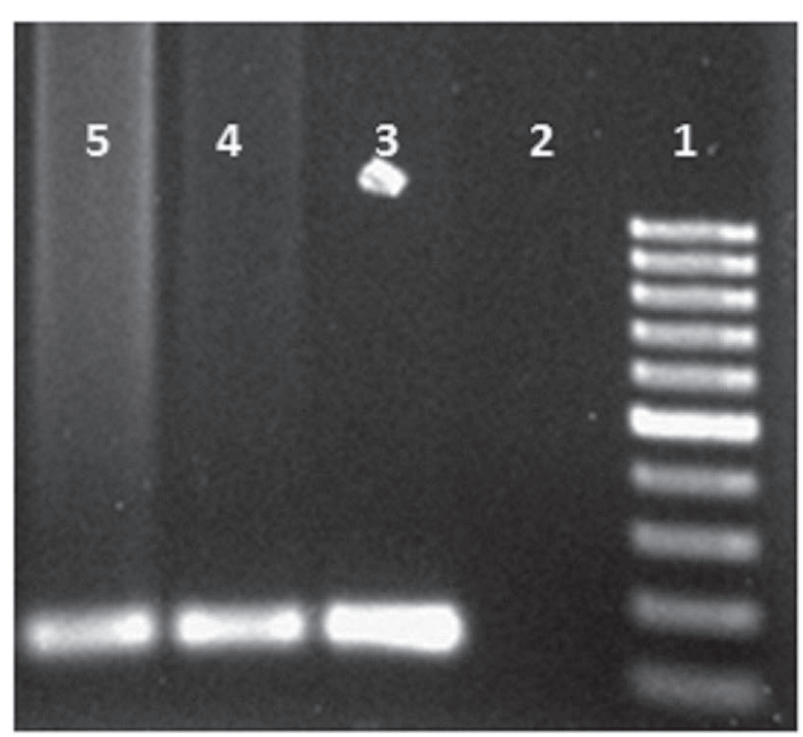

Figure 1. The First, Second, Third, Fourth and the Fifth Lanes Representing 100 bp Marker, Negative Control, Positive Control, Positive Blood Sample, and Positive Pulmonary Lavage Sample Respectively.

\begin{tabular}{|c|c|c|c|c|c|c|}
\hline \multirow[t]{2}{*}{ PCR } & \multicolumn{2}{|c|}{ ELISA IgG } & \multirow[t]{2}{*}{ Total } & \multicolumn{2}{|c|}{ ELISA IgM } & \multirow[t]{2}{*}{ Total } \\
\hline & Negative & Positive & & Negative & Positive & \\
\hline \multicolumn{7}{|l|}{ Negative } \\
\hline Count & 22 & 25 & 47 & 47 & 0 & 47 \\
\hline \% Within ELISA & 95.7 & 92.6 & 94 & 97.9 & 0 & 94 \\
\hline \multicolumn{7}{|l|}{ Positive } \\
\hline Count & 1 & 2 & 3 & 1 & 2 & 3 \\
\hline \% Within ELISA & 4.3 & 7.4 & 6 & 2.1 & 100 & 6 \\
\hline \multicolumn{7}{|l|}{ Total } \\
\hline Count & 23 & 27 & 50 & 48 & 2 & 50 \\
\hline \% Within ELISA & 100 & 100 & 100 & 100 & 100 & 100 \\
\hline
\end{tabular}

specificity of PCR in detecting Toxoplasmosis was100\% and $97.9 \%$, respectively (Table 3 ).

Statistical analysis showed no significant relationship between the age, duration of renal transplant in patients and IgG, IgM titers and PCR. There was no significant relationship between gender and IgM level and PCR. There was a significant correlation between positive IgG antibody level and female patients in this study.

\section{Discussion}

Immune system disorders in transplant recipients and cancer patients dispose these patients to infection of a variety of opportunistic pathogens due to immunosuppressive drugs intake(11). Toxoplasma gondii is considered as an opportunistic infectious microorganism among immunosuppressed patients. The first case of Toxoplasmosis in Iran was reported by Ansari et al. in 1948, which was isolated from conjunctiva of a 9-year old youngster (12). Toxoplasma gondii can cause multiple organ infection in immunosuppressed patients, such as lung secondary to CNS infection. Among patients with immune system disorders, patients with AIDS showed the highest prevalence of Toxoplasma pneumonia (13).

Many studies have reported a high incidence of cerebral and disseminated toxoplasmosis after receiving a kidney 
transplant. The anti-toxoplasma gondii prophylaxis can be directly related to decreased amount of toxoplasmosis. In patients receiving kidney transplants, the incidence of IgM antibody has been reported to be $24.1 \%$ within the first year of transplantation (14).

In this study, 50 blood samples, collected from transplant recipients, were assessed for IgG and IgM antibodies. Our results showed that the prevalence of antitoxoplasma IgG and IgM antibodies were $54 \%$ and $4 \%$, respectively. These results were in accordance with the results of Keshavarz (15). In our study, a significant correlation was found between positive IgG antibody level and female gender. There have been several reports of pulmonary toxoplasmosis inpatients receiving kidney, heart, bone marrow, liver, stem cell, pancreas and lung transplants (16-21).

Toxoplasma gondii pneumonia is diagnosed by different methods including serological tests, culturing and isolation of the microorganism. Derouin and colleagues in 1989 had detected the Toxoplasma pneumonia in three BAL samples and an autopsy specimen of patients with immune deficiency, by Methylene blue staining, indirect immunofluorescence and growing on MRC5 medium of (22).

Diagnosis of pulmonary toxoplasmosis in patients by molecular methods is important in immunosuppressed patients undergoing bronchoscopy due to the respiratory problems. The results have shown that the highest prevalence of pulmonary toxoplasmosis is reported among patients with AIDS, which has been up to $14 \%$ (23).

Molecular diagnosis of Toxoplasma gondii in our study was conducted on 40 lung lavage samples of renal transplant recipients. The results showed that 2 samples (5\%) were positive for Toxoplasma gondii. Molecular diagnosis of toxoplasmosis among immunosuppressed non-AIDS patients showed a prevalence of 2 to $6.4 \%$ of pulmonary toxoplasmosis, which was consistent with our results $(24,25)$.

Chronic toxoplasmosis infection is directly associated with the use of immune-suppressive drugs and anti-Toxoplasma gondii prophylaxis. In patients receiving a kidney transplant who had negative Toxoplasma antibody before the transplantation, cessation of prophylaxis leaded to positive antibody against Toxoplasmosis $(26,27)$.

Detection of Toxoplasma gondii using PCR can be valuable in aligns with serological methods. PCR is very important method for appropriate diagnosis of pulmonary toxoplasmosis due to the high rate of mortality and morbidity rate of cases with toxoplasmosis (28). The screening of anti-Toxoplasma gondii antibodies in organ transplant patients without chronic infection is important once the donor with chronic Toxoplasma infection can transmit the infection to healthy transplant recipient (29). In this regard, screening of anti-Toxoplasma gondii antibodies in kidney donors and recipients is recommended before and after transplantation.

\section{Acknowledgements}

We wish to acknowledge Dr. Mirhendi for his valuable assistance. The authors deeply appreciate all the patients who were involved in this study.

\section{Authors' Contribution}

Study Design: Babak Rezavand, Morteza Izadi, Nematollah Joneidi Jafari; Statistical analysis: Babak Rezavand, Abulfazl Khedive; Sample collection: Babak Rezavand, Hossein Zarrinfar, Abulfazl Khedive; PCR procedures: Babak Rezavand, Abulfazl Khedive; Manuscript wiring and preparation: Babak Rezavand, Javid Sadraei, Morteza Izadi, Abbas Mahmoodzadeh Poornaki; PCR data analysis: Babak Rezavand, Abbas Mahmoodzadeh Poornaki, Hamid Reza Mirzaei; Serological Studies: Babak Rezavand, Hamid Reza Mirzaei.

\section{Financial Disclosure}

This study had no financial sponsor.

\section{Funding/Support}

This study was supported by Health Research Center, Baqiatallah University of Medical Sciences.

\section{References}

1. Joynson David HM, Wreghitt Tim G. Toxoplasmosis: a comprehensive clinical guide: Cambridge University Press; 2005.

2. Dubey JP. The history of Toxoplasma gondii--the first 100 years. $J$ Eukaryot Microbiol. 2008;55(6):467-75.

3. Webster JP. Rats, cats, people and parasites: the impact of latent toxoplasmosis on behaviour. Microbes Infect. 2001;3(12):1037-45.

4. Wyler David J. Modern parasite biology: cellular, immunological, and molecular aspects. Oxford: WH Freeman and Company Limited; 1990.

5. Israelski DM, Remington JS. Toxoplasmosis in the non-AIDS immunocompromised host. Curr Clin Top Infect Dis. 1993;13:322-56.

6. Remington JS, Thulliez P, Montoya JG. Recent developments for diagnosis of toxoplasmosis. J Clin Microbiol. 2004;42(3):941-5.

7. Hill D, Dubey JP. Toxoplasma gondii: transmission, diagnosis and prevention. Clin Microbiol Infect. 2002;8(10):634-40.

8. Pomeroy C, Filice GA. Pulmonary toxoplasmosis: a review. Clin Infect Dis. 1992;14(4):863-70.

9. Ryning FW, McLeod R, Maddox JC, Hunt S, Remington JS. Probable transmission of Toxoplasma gondii by organ transplantation. Ann Intern Med. 1979;90(1):47-9.

10. Decoster A, Slizewicz B, Simon J, Bazin C, Darcy F, Vittu G, et al. Platelia-Toxo IgA, a new kit for early diagnosis of congenital toxoplasmosis by detection of anti-P30 immunoglobulin A antibodies. J Clin Microbiol.1991;29(10):2291-5.

11. Ehrke MJ, Mihich E, Berd D, Mastrangelo MJ. Effects of anticancer drugs on the immune system in humans. Seminars in oncology; 1989. p. 230-53

12. Saebi E. Parasitic Diseases in Iran. 7th ed. Tehran: Hayyan; 2003.

13. Catterall JR, Hofflin JM, Remington JS. Pulmonary toxoplasmosis. Am Rev Respir Dis. 1986;133(4):704-5.

14. Aufy SM, Mahgoub AM, Saadi MG, Adel Elmallawany M. Serological detection of Toxoplasma gondii in chronic renal failure patients and renal transplant recipients. J Egypt Soc Parasitol. 2009;39(3):943-50.

15. Rostami M Nateghi, Eskandari E, Garoosi Z, Mohajeri N, Rezaian 
M, Keshavarz H. Serological Study of Toxoplasma gondii Infection Using IFA Method in Renal Transplant Recipients. Iran J Parasitol. 2006;1(1):31-9.

16. Barcan LA, Dallurzo ML, Clara LO, Valledor A, Macias S, Zorkin E, et al. Toxoplasma gondii pneumonia in liver transplantation: survival after a severe case of reactivation. Transpl Infect Dis. 2002;4(2):93-6.

17. Martina MN, Cervera C, Esforzado N, Linares L, Torregrosa V, Sanclemente $\mathrm{G}$, et al. Toxoplasma gondii primary infection in renal transplant recipients. Two case reports and literature review. Transpl Int. 2011;24(1):e6-12.

18. Martino R, Maertens J, Bretagne S, Rovira M, Deconinck E, Ullmann AJ, et al. Toxoplasmosis after hematopoietic stem cell transplantation. Clin Infect Dis. 2000;31(5):1188-95.

19. Munir A, Zaman M, Eltorky M. Toxoplasma gondii pneumonia in a pancreas transplant patient. South Med J. 2000;93(6):614-7.

20. Orr KE, Gould FK, Short G, Dark JH, Hilton CJ, Corris PA, et al. Outcome of Toxoplasma gondii mismatches in heart transplant recipients over a period of 8 years. J Infect. 1994;29(3):249-53.

21. Sing A, Leitritz L, Roggenkamp A, Kolb HJ, Szabados A, Fingerle V, et al. Pulmonary toxoplasmosis in bone marrow transplant recipients: report of two cases and review. Clin Infect Dis.1999;29(2):429-33.

22. Derouin F, Sarfati C, Beauvais B, Garin YJ, Lariviere M. Prevalence of pulmonary toxoplasmosis in HIV-infected patients. AIDS. 1990;4(10):1036.

23. Bretagne S, Costa JM, Vidaud M, Tran J, Nhieu V, Fleury-Feith J. Detection of Toxoplasma gondii by competitive DNA amplification of bronchoalveolar lavage samples. J Infect Dis. 1993;168(6):1585-8.

24. Petersen E, Edvinsson B, Lundgren B, Benfield T, Evengard B. Diagnosis of pulmonary infection with Toxoplasma gondii in immunocompromised HIV-positive patients by real-time PCR. Eur J Clin Microbiol Infect Dis. 2006;25(6):401-4.

25. Roth A, Roth B, Hoffken G, Steuber S, Khalifa KI, Janitschke K. Application of the polymerase chain reaction in the diagnosis of pulmonary toxoplasmosis in immunocompromised patients. Eur J Clin Microbiol Infect Dis. 1992;11(12):1177-81.

26. Baden LR, Katz JT, Franck L, Tsang S, Hall M, Rubin RH, et al. Successful toxoplasmosis prophylaxis after orthotopic cardiac transplantation with trimethoprim-sulfamethoxazole. Transplantation. 2003;75(3):339-43.

27. Soave R. Prophylaxis strategies for solid-organ transplantation. Clin Infect Dis. 2001;33 Suppl 1:S26-31.

28. Robert-Gangneux F, Darde ML. Epidemiology of and diagnostic strategies for toxoplasmosis. Clin Microbiol Rev. 2012;25(2):264-96.

29. Derouin F, Pelloux H. Prevention of toxoplasmosis in transplant patients. Clin Microbiol Infect. 2008;14(12):1089-101. 